\title{
28 Research Square \\ Self-stigma and associated factors among \\ Outpatients with Schizophrenia in low income East African countries: Ethiopia
}

Hailemarim Hailesilasiie Weldemariam ( $\sim$ hailemariamh2011@gmail.com )

Jimma University

Hagos Tsegabrihan

Mekelle University College of Health Sciences

Research article

Keywords: self-stigma, schizophrenia, East Africa, Ethiopia

Posted Date: September 6th, 2019

DOI: https://doi.org/10.21203/rs.2.13958/v1

License: (c) (1) This work is licensed under a Creative Commons Attribution 4.0 International License.

Read Full License 


\section{Abstract}

Background Even though there are efforts to expand of psychiatric treatment and recovery, there is limited data on the extent that self stigma complicates the psychiatric treatment adherence and lives of outpatients with schizophrenia in low income East African countries. This study was conducted with aim determine distribution of self stigma and associated socio-demographic and clinical factors among outpatients with schizophrenia in Ethiopia.

Methods the study was an institution based cross-sectional conducted at Ayder Referral Hospital, Northern Ethiopia. Single population proportion formula was used to calculate sample size. Consecutive consenting outpatients with schizophrenia selected and assessed using Tigrigna version of the perceived devaluation and discrimination scale.

Result data was collected from 2016 outpatients with schizophrenia; with response rate of $92.7 \%$, who were males $(70.8 \%)$, single (59.7\%), within age range of 23 to34 years $(42.1 \%)$, (Orthodox in religion (81.6\%), could not read and write (52.8\%), unemployed (86.6\%), living in rural areas (55.1\%) and with their family (82.9\%). The mean ages of the participants were 32.9 years. $67.1 \%$ of the study participants reported self stigma. Factors such as being single (AOR=6.2, 95\% $\mathrm{Cl}=1.83-21.21)$, rural resident $(A O R=3.7,95 \% \mathrm{Cl}=1.47-9.14$ ), living alone ( $A O R=9.5,95 \% \mathrm{Cl}=1.59-56.40)$, low educational status ( $A O R=$ $13.4,95 \% \mathrm{Cl}=2.1-13.16)$, being with the illness with delayed treatment for more than eleven years ( $A O R=11.6,95 \% \mathrm{Cl}=2.19-61.7)$, non-adherence to clinical follow up ( $\mathrm{AOR}=10.6,95 \% \mathrm{Cl}=2.96-12.7)$ and medications non-adherence ( $\mathrm{AOR}=3.7,95 \% \mathrm{Cl}=1.10-12.37$ ) were positively significantly associated with self stigma of outpatients with schizophrenia.

Conclusion and Recommendation self stigma is major problem of outpatients with schizophrenia of low income country Ethiopia. Especially, self stigma complicates the lives of single and low educational level persons with schizophrenia and is likely disrupt the psychiatric treatment and recovery process. Our findings recommend that non-governmental and international charity organizations shall help persons with schizophrenia reduce their self stigma.

\section{Introduction}

Schizophrenia is severe, chronic and disabling mental disorder by which around 24million people worldwide are suffering from it (1). Even in Ethiopia, both schizophrenia and depression are the top ten most burdensome conditions, out-ranking HIV/AIDS (2). Schizophrenia is a severe disorder that typically begins in late adolescence or early adulthood. It is characterized by fundamental distortions in thinking and perception, and by inappropriate emotions.

Stigma is a barrier which prevents persons with mental illness from accessing and receiving the help and psychiatric treatment and stay well (3). This condition is becomes 
severe and problematic for people with severe mental disorders such as schizophrenia (4, $5)$.

Self stigma or internalized stigma is considered when persons with mental illness identify themselves with the stigmatized group and apply corresponding stereotypes and prejudices to the self (6). Available evidence showed that self-stigma negatively affects the lives of people with severe mental illness such as impacts on self-esteem (7), recovery from the illness, social relationships (8), treatment adherence, willingness to seek help (9).

Ample researches in developed countries reported that stigmatization of people with mental illnesses and its negative consequences. For instance, a study done in Singapore showed as a result of self-stigma, outpatient with schizophrenia faced difficulty in finding a job (73\%), thoughtless of themselves because of their illness (52\%), felt ashamed of their illness (47\%) (10). Another study done 14 European countries reported that self stigma was higher and complicated the lives of schizophrenic outpatients with status of unemployment, lower educational level, female gender, and being unsure with schizophrenia diagnosis (11).

However, in low income East African countries like Ethiopia, there is little data which could show the members of communities with schizophrenia who are suffering from self stigma. Therefore, this study was conducted with aim to determine self stigma and identified vulnerable groups of outpatients with schizophrenia.

\section{Materials And Methods}

Study design and Setting: An institution based cross-sectional study design was used to assess the self-stigma and associated variables among outpatients with schizophrenia in Ayder referral Hospital, Northern Ethiopia.

Study Participants: The study was conducted among 233 adult outpatients with schizophrenia. They were selected consecutively based on the eligibility criteria. Sample size of the study was determined using single population proportion formula. Selected eligible participants were interviewed using the study questionnaire. Participants with difficulty of communication were excluded from the study.

Measurement: Perceived devaluation and discrimination (PDD) scale with 12-items was used to measure the self-stigma outpatients with schizophrenia. The PDD is a 12-item tool, which measures the extent to which a person believes that most people will devalue or discriminate against someone with a mental illness (12). PDD is measured on a 4-point Likert scale with possible scores ranging from 1 to 4 agreement scale $(1=$ strongly disagree, 2 = disagree, 3 = agree, and $4=$ strongly agree), this scale has been widely used across the world including Africa (13) and has excellent psychometric properties (14). Items 1, 2, 3, 4, 8, and 10 will be reverse-scored. Prior to actual data collection, the investigators pre-tested the PDD scale on $10 \%$ of the study participants among 
schizophrenic outpatients of Amanuel Mental Hospital. Accordingly, the reliability of the pre-tested PDD with 12-items was Cronbach's alpha of 92.05. Data was collected by faceto-face interview among eligible participants.

Self-stigma: refers to the feeling or belief that a schizophrenic outpatient is said to have high self-stigma when he/she scored 2.5 and above on PDD scale and vice versa.

Statistical Analysis: The collected data were analyzed to give descriptive statistics such as means, standard deviation, frequencies, and percentages using statistical package for social sciences (SPSS version 20). Besides, bivariate and multi-variable logistic regression was used to identify factors accounting for the self-stigma of outpatients with schizophrenia. P-value less than 0.05 were taken to notify statistical significance.

Ethical Approval: The study obtained ethical approval from institution of research review board of College of Health Sciences of Mekele University. An information sheet was attached with each questionnaire and the data collectors read it as well. All participants were reassured privacy and their right in the study. Written informed consent was obtained from the study participants. Data were kept anonymous and confidential during all stages of the study.

\section{Results}

\section{Background Characteristics}

From the total of 233 schizophrenia outpatients, 216 of them participated in the study and having response rate of $92.7 \%$. The remaining participants failed to complete the interview because of the illness, in between the study, and questions were not fulfilled properly.

The majority of the Participants were males 153 (70.8\%). The mean ages of the participants were 32.9 years. Out of the total study participants, $114(52.8 \%)$ of them could not read and write, Orthodox in religion 176(81.6\%), single in marital status 129(59.7\%), and within the age range of 25-34 years $91(42.1 \%)$.

Out of 216 participants, 187(86.6\%) were unemployed, 119 (55.1\%) were living in rural areas, and 179 (82.9\%) were living with their family (Table 1).

Table 1: Socio demographic characteristics of the study participants $(n=216)$ 


\begin{tabular}{|c|c|c|c|}
\hline Variable & Categories & Frequency $(\mathrm{N})$ & Percentage (\%) \\
\hline \multirow{2}{*}{ Sex } & Male & 153 & 70.8 \\
\hline & Female & 63 & 29.2 \\
\hline \multirow[t]{4}{*}{ Age } & $18-24$ & 38 & 17.6 \\
\hline & $25-34$ & 91 & 42.1 \\
\hline & $35-44$ & 64 & 29.6 \\
\hline & $\geq 45$ & 23 & 10.7 \\
\hline \multirow{4}{*}{ Marital status } & Single & 129 & 59.7 \\
\hline & Married & 46 & 21.3 \\
\hline & Divorced & 30 & 13.9 \\
\hline & Widowed & 11 & 5.1 \\
\hline \multirow[t]{3}{*}{ Educational status } & Cannot read and write & 114 & 52.8 \\
\hline & Primary school & 81 & 37.5 \\
\hline & Secondary and above & 21 & 9.7 \\
\hline \multirow[t]{4}{*}{ Ethnicity } & Tigray & 202 & 93.5 \\
\hline & Afar & 11 & 5.1 \\
\hline & Amhara & 1 & 0.5 \\
\hline & Others & 2 & 0.9 \\
\hline \multirow[t]{4}{*}{ Religion } & Muslim & 31 & 14.4 \\
\hline & Orthodox & 176 & 81.4 \\
\hline & Protestant & 4 & 1.9 \\
\hline & Catholic & 5 & 2.3 \\
\hline \multirow[t]{2}{*}{ Employment status } & Unemployed & 187 & 86.6 \\
\hline & Employed & 29 & 13.4 \\
\hline \multirow[t]{2}{*}{ Residence } & Rural & 119 & 55.1 \\
\hline & Urban & 97 & 44.9 \\
\hline \multirow[t]{2}{*}{ Living arrangement } & With family & 179 & 82.9 \\
\hline & Alone & 37 & 17.1 \\
\hline
\end{tabular}

\section{Clinical Characteristics of the study participants}

$32.9 \%$ (71) of the participants had been for two to five years with schizophrenia. Though $18 \%$ (39) of participants had the illness of schizophrenia for eleven and above years, only $6.9 \%$ (15) persons had treatment since the illness onset. Out of the total of the study participants, $18.9 \%$ ( 39) and $30.6 \%$ (66) of them had difficulty of adherence to prescribed anti-psychotic medications and follow up appointments, respectively (table 2). Table2: clinical characteristics of the study participants $(n=216)$ 


\begin{tabular}{|c|c|c|c|}
\hline Variable & Categories & $\begin{array}{l}\text { Frequency } \\
\text { (N) }\end{array}$ & $\begin{array}{l}\text { Percentage } \\
\text { (\%) }\end{array}$ \\
\hline \multirow[t]{4}{*}{ Duration of illness } & $\leq 1$ year & 43 & 19.9 \\
\hline & 2-5 years & 71 & 32.9 \\
\hline & $6-10$ years & 63 & 29.2 \\
\hline & $\geq 11$ years & 39 & 18 \\
\hline \multirow[t]{4}{*}{ Duration of treatment } & $\leq 1$ year & 69 & 31.9 \\
\hline & 2-5 years & 93 & 43.1 \\
\hline & $6-10$ years & 39 & 18.1 \\
\hline & $\geq 11$ years & 15 & 6.9 \\
\hline \multirow[t]{2}{*}{ Adherence to prescribed drugs } & Yes & 177 & 81.9 \\
\hline & No & 39 & 18.9 \\
\hline \multirow{2}{*}{$\begin{array}{l}\text { Adherence to clinical follow up or } \\
\text { appointment }\end{array}$} & Yes & 150 & 69.4 \\
\hline & No & 66 & 30.6 \\
\hline
\end{tabular}

\section{Prevalence Self-stigma among the study participants}

The study found that prevalence of self-stigma among schizophrenic outpatients was $67.1 \%$ (145) (figure 1).

Large proportion of schizophrenia patients with adherence to prescribed psychotropic drugs medication experience self-stigma (72.3\%) as compared those patient with no psychotropic drugs adherence (43.6\%). On the other hand, large proportion schizophrenic patients with more than eleven years illness duration before treatment reported self-stigma (84.6\%) compared to those patients with up to one year untreated illness duration (48.8\%). Large proportion of rural residents of schizophrenic patients reported self-stigma (79.8\%) compared to urban resident counter parts (51.5\%). While $80.7 \%$ of patients who cannot read and write reported self-stigma, $28.6 \%$ of patients with secondary and above educational status had self-stigma (Table3).

Table 3: Cross tab analysis factors versus self-stigma status 


\begin{tabular}{|c|c|c|c|c|}
\hline \multirow[t]{2}{*}{ Factors } & \multirow[t]{2}{*}{ Category } & \multicolumn{3}{|c|}{ Self-stigma status } \\
\hline & & No & Yes & $\begin{array}{l}\mathrm{p} \text { - } \\
\text { value }\end{array}$ \\
\hline \multirow[t]{2}{*}{ Adherence to prescribed drugs } & Yes & $27.7 \%$ & $72.3 \%$ & \multirow[t]{2}{*}{0.001} \\
\hline & No & $56.4 \%$ & $43.6 \%$ & \\
\hline \multirow{2}{*}{$\begin{array}{lllll}\begin{array}{l}\text { Adherence to clinical follow up or } \\
\text { appointment }\end{array} & & & & \text { or } \\
\end{array}$} & Yes & $41.3 \%$ & $58.7 \%$ & \multirow[t]{2}{*}{0.000} \\
\hline & No & $13.6 \%$ & $86.4 \%$ & \\
\hline \multirow[t]{4}{*}{ Duration of the illness before treatment } & $<$ or $=1$ year & $51.2 \%$ & $48.8 \%$ & \multirow[t]{4}{*}{0.004} \\
\hline & 2 -5years & $36.6 \%$ & $63.4 \%$ & \\
\hline & 6-10years & $27.0 \%$ & $73.0 \%$ & \\
\hline & $>$ or $=11$ years & $15.4 \%$ & $84.6 \%$ & \\
\hline \multirow[t]{4}{*}{ Duration of treatment } & $\leq 1$ year & $18.8 \%$ & $81.2 \%$ & \multirow[t]{4}{*}{0.001} \\
\hline & $2-5$ years & $32.3 \%$ & $67.7 \%$ & \\
\hline & $6-10$ years & $48.7 \%$ & $51.3 \%$ & \\
\hline & $\geq 11$ years & $60.0 \%$ & $40.0 \%$ & \\
\hline \multirow[t]{2}{*}{ Living arrangement } & With family & $37.4 \%$ & $62.6 \%$ & \multirow[t]{2}{*}{0.002} \\
\hline & Alone & $10.8 \%$ & $89.2 \%$ & \\
\hline \multirow{2}{*}{ Residence } & Rural & $20.2 \%$ & $79.8 \%$ & \multirow[t]{2}{*}{0.000} \\
\hline & Urban & $48.5 \%$ & $51.5 \%$ & \\
\hline \multirow{4}{*}{ Marital status } & Single & $25.6 \%$ & $74.4 \%$ & \multirow[t]{4}{*}{0.000} \\
\hline & Married & $58.7 \%$ & $41.3 \%$ & \\
\hline & Divorced & $36.4 \%$ & $63.6 \%$ & \\
\hline & Widowed & $23.3 \%$ & $76.7 \%$ & \\
\hline \multirow[t]{3}{*}{ Educational status } & $\begin{array}{lll}\text { Cannot read and } \\
\text { write }\end{array}$ & $19.3 \%$ & $80.7 \%$ & \multirow[t]{3}{*}{0.000} \\
\hline & Primary school & $42.0 \%$ & $58.0 \%$ & \\
\hline & $\begin{array}{l}\text { Secondary and } \\
\text { above }\end{array}$ & $71.4 \%$ & $28.6 \%$ & \\
\hline \multirow[t]{2}{*}{ Gender } & Male & $26.8 \%$ & $73.2 \%$ & \multirow[t]{2}{*}{0.003} \\
\hline & Female & $47.6 \%$ & $52.4 \%$ & \\
\hline \multirow[t]{2}{*}{ Employment status } & Unemployed & $26.2 \%$ & $73.8 \%$ & \multirow[t]{2}{*}{0.000} \\
\hline & Employed & $75.9 \%$ & $24.1 \%$ & \\
\hline \multirow[t]{4}{*}{ Religion } & Muslim & $32.3 \%$ & $67.7 \%$ & \multirow[t]{4}{*}{$\overline{0.972}$} \\
\hline & Orthodox & $33.0 \%$ & $67.0 \%$ & \\
\hline & Protestant & $25.0 \%$ & $75.0 \%$ & \\
\hline & Catholic & $40.0 \%$ & $60.0 \%$ & \\
\hline \multirow{4}{*}{ Ethnicity } & Tigray & $33.2 \%$ & $66.8 \%$ & 0.364 \\
\hline & Afar & $27.3 \%$ & $72.7 \%$ & \\
\hline & Amhara & $100.0 \%$ & $0.0 \%$ & \\
\hline & Others & $0.0 \%$ & $100.0 \%$ & \\
\hline Age & $18-24$ & $23.7 \%$ & $76.3 \%$ & 0.359 \\
\hline & $25-34$ & $38.5 \%$ & $61.5 \%$ & \\
\hline & $35-44$ & $32.8 \%$ & $67.2 \%$ & \\
\hline & $\geq 45$ & $26.1 \%$ & $73.9 \%$ & \\
\hline
\end{tabular}


In binary logistic regression analysis, factors such as being male (COR $=2.5,95 \% \mathrm{CI}=1.35$ 4.57), single $(\mathrm{COR}=4.13,95 \% \mathrm{CI}=2.04-8.39)$, widowed $(\mathrm{COR}=4.67,955 \mathrm{CI}=1.67-13.10)$, rural resident $(\mathrm{COR}=3.72,95 \% \mathrm{CI}=2.04-6.77)$, living alone $(\mathrm{COR}=4.94,95 \% \mathrm{CI}=1.67-$ 14.55), cannot read and write $(\mathrm{COR}=10.46,95 \% \mathrm{CI}=3.64-30.0)$, having primary school educational level $(\mathrm{COR}=3.46,95 \% \mathrm{CI}=1.22-9.82)$, being employed $(\mathrm{COR}=0.11,95 \%$ $\mathrm{CI}=0.05-0.28$ ), being with schizophrenia without treatment for eleven and above years $(\mathrm{COR}=5.76,95 \% \mathrm{CI}=2.01-16.56)$, less than one year schizophrenia treatment $(\mathrm{COR}=6.46$, 95\% $\mathrm{CI}=1.95-21.37$ ), two to five schizophrenia treatment (COR=3.15, 95\% CI=1.03-9.66), no adherence to clinical follow appointments ( $\mathrm{COR}=4.46,95 \% \mathrm{CI}=2.06-9.68)$, and being medication non-adherent $(\mathrm{COR}=3.38,95 \% \quad \mathrm{CI}=1.66-6.90)$ significantly independently associated Self-stigma of outpatients with schizophrenia.

After controlling potential confounders by multivariate logistic regression, being single marital status $(\mathrm{AOR}=6.2,95 \% \mathrm{CI}=1.83-21.21)$, rural resident $(\mathrm{AOR}=3.7,95 \% \mathrm{CI}=1.47$ 9.14), being living alone $(\mathrm{AOR}=9.5,95 \% \mathrm{CI}=1.59-56.40)$, cannot read and write $(\mathrm{AOR}=22.2,95 \% \mathrm{CI}=3.5-15.85)$, primary school educational status and below $(\mathrm{AOR}=13.4$, 95\% CI=2.1-13.16), staying with schizophrenia illness for eleven and above years without treatment $(\mathrm{AOR}=11.6,95 \% \mathrm{CI}=2.19-61.7)$, having less than a year schizophrenia treatment (AOR=49.1, 95\% CI=5.1-15.46), two to five years of treatment of schizophrenia ( $A O R=10.2,95 \% C I=1.23-9.25)$, non-adherence to clinical follow up (AOR=10.6, 95\% $\mathrm{CI}=2.96-12.7$ ), and being non-adherent to medications (AOR=3.7, 95\% $\mathrm{CI}=1.10-12.37$ ) was positively significantly associated with Self-stigma among persons with schizophrenia visiting outpatient clinic. However, being male, widowed didn't significantly associate with schizophrenia outpatient Self-stigma condition. On the other hand, being unemployed (AOR=0.1, 95\% CI= 0.02-0.29) negatively associated with Self-stigma of persons with schizophrenia treated at outpatient department.

The odds of developing Self-stigma was six times higher among single schizophrenic outpatients than that of married ones ( $\mathrm{AOR}=6.2,95 \% \mathrm{CI}=1.83-21.21$ ). Besides, schizophrenic outpatients living in rural areas had almost four times odds of higher Selfstigma compared to those from urban areas (AOR=3.7, 95\% CI=1.47-9.14). The odds of Self-stigma was almost ten times higher among schizophrenic outpatients who lived alone than those who lived with their relatives ( $A O R=9.5,95 \% \mathrm{CI}=1.59-56.40)$. On the other hand, schizophrenic outpatients who cannot read and write (AOR=22.2, 95\% CI= 3.515.85) and primary school educational status and below (AOR=13.4, 95\% CI=2.1-13.16) had twenty two and more than thirteen times, respectively, of Self-stigma compared to schizophrenic outpatients with secondary school and above educational status. The odds of Self-stigma was more than eleven times higher among persons with schizophrenia outpatients who stayed with schizophrenia illness for eleven and above years without treatment $(\mathrm{AOR}=11.6,95 \% \mathrm{CI}=2.19-61.7)$ than that of persons with less than a year schizophrenia illness duration. Besides, persons with less than a year (AOR=49.1, 95\% 
$\mathrm{CI}=5.1-15.46)$ and two to five years of schizophrenia treatment (AOR=10.2, 95\% CI=1.239.25) in outpatient department had forty nine times and more than times, respectively, higher odds of Self-stigma compared to that of schizophrenic outpatients with eleven and above years of treatment duration. Moreover, the odds of Self-stigma was more than ten times higher among schizophrenic outpatients who were non-adherent to clinical follow up compared to those schizophrenic outpatients with good adherence to clinical follow up appointments $(\mathrm{AOR}=10.6,95 \% \mathrm{CI}=2.96-12.7)$. In addition to this, medication non-adherent schizophrenic outpatients had more than three times higher odds of Self-stigma than medication adherent outpatients with schizophrenia (AOR=3.7, 95\% CI=1.10-12.37). Furthermore, the odds of Self-stigma was lower among unemployed schizophrenic outpatients as compared to that of employed ones ( $\mathrm{AOR}=0.1,95 \% \mathrm{CI}=0.02-0.29$ ) (Table 4).

Table 4: Logistic regression analysis results on factors predicting Self-stigma among Schizophrenia outpatients 


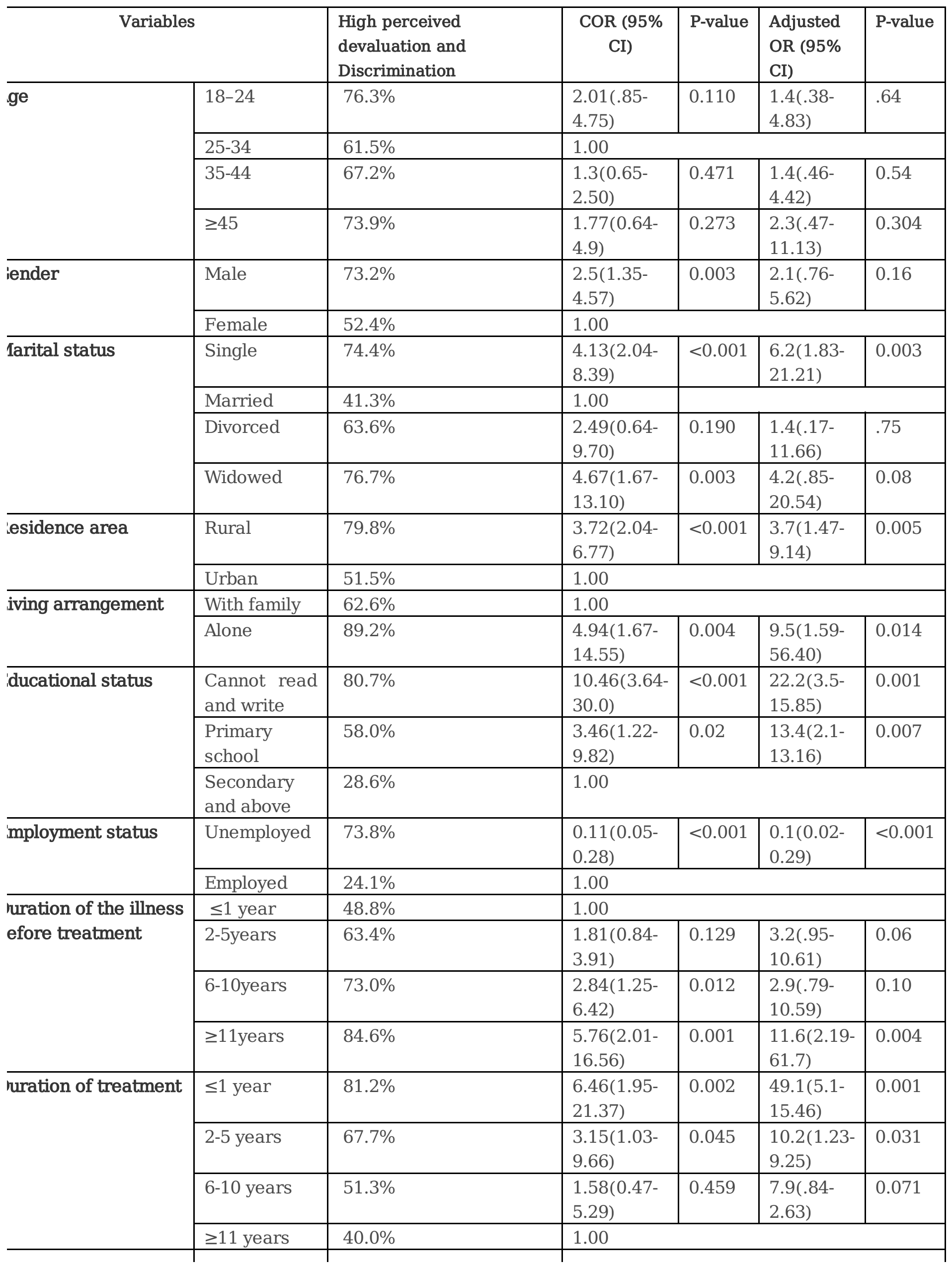




\begin{tabular}{|c|c|c|c|c|c|c|}
\hline \multirow{2}{*}{$\begin{array}{l}\text { 'linical follow up } \\
\text { dherence }\end{array}$} & \multirow{2}{*}{\begin{tabular}{|l} 
Yes \\
No
\end{tabular}} & \multirow{2}{*}{$\begin{array}{l}58.7 \% \\
86.4 \%\end{array}$} & \multicolumn{4}{|l|}{1.00} \\
\hline & & & $\begin{array}{l}4.46(2.06- \\
9.68)\end{array}$ & $<0.001$ & $\begin{array}{l}10.6(2.96- \\
12.7)\end{array}$ & $<0.001$ \\
\hline \multirow[t]{2}{*}{ rug Adherence } & No & $72.3 \%$ & $\begin{array}{l}3.38(1.66- \\
6.90)\end{array}$ & 0.001 & $\begin{array}{l}3.7(1.10- \\
12.37)\end{array}$ & 0.034 \\
\hline & Yes & $43.6 \%$ & \multicolumn{4}{|l|}{1.00} \\
\hline
\end{tabular}

Constant $=-9.67$, Wald $=27.03$, Reference $=1.00$

\section{Discussion}

This study assessed the prevalence of self-stigma among outpatients with schizophrenia in Ayder Referral Hospital of psychiatry clinic with the methodological design of cross sectional type.

This study found that one month prevalence of Self-stigma was 67.1\%. This finding is similar with other cross-sectional studies in study waslio similar when compared with the cross-sectional study carried out across 14 European countries using the same tool which reported $69.4 \%$ (11). and a systematic review of studies including 54 published studies from 1994 to 2011 also reported on average $64.5 \%$ of participants' self-stigma (15) and this little difference may be due to the back ground of the participants and awareness variation. However, the study self-stigma prevalence rate was contradicted with previous facility based cross-sectional study, which was conducted at Amanuel Mental Specialized Hospital; Ethiopia in 2012 among participants with schizophrenia, finding (83.5\%) (13). This variation could be that due to the passage of time, there may be improvements on mental health issues through various electronic as well as social media.

We found that single schizophrenic outpatients have six times of odds of developing Selfstigma as compared to married ones. This finding is contradicted with research result which done in Croatia stating that there was no statistical significant difference of self stigma among single and married outpatient schizophrenia (16). This could be that in Ethiopia there are little social organizations that give take care of schizophrenic people that could share their emotional feelings.

Our study found that the odd of having Self-stigma is almost four times higher among rural schizophrenic outpatients than urban ones. This could be due to the reason that rural people with schizophrenia have fewer options such as educational, technological, and social skill developments for managing the difficulties of their illness. This result is confirmed with previous finding in Ethiopia by Laura Asher et al., (2014) (17) which stated the importance of building community based rehabilitation.

Family support is very important in reducing stigma among schizophrenic patients. In our study, schizophrenic patients who live alone reported ten times of chance of developing 
Self-stigma as compared to those patients living with their relatives. This indicates that loneliness among schizophrenia outpatients could exacerbate burden their illness and worsens their self-stigma whereas schizophrenia outpatient with family support could minimize the burden of their illness. Because traditional Ethiopians value and belief mental illness as a punishment or God's curse for one's misdeeds, possession off devil and people with mental illness experience severe social discrimination and rejection (18).

As patients with schizophrenia get educated, their chance of suffering from stigma could be reduced. To this support, this study found that schizophrenic outpatients who cannot read and write had twenty two of Self-stigma compared to schizophrenic outpatients with secondary school and above educational status. This outcome is contradicted with studies done in 14 European countries which reported that level of education was significant predictor of self stigma, which used the same scale of PDD (11). The same research report, which was conducted in University Hospital Olomouc Czech Republic, stated that educational level was not predicting self-stigma among outpatients with schizophrenia (19). These differences could be cultural differences as in Ethiopia, around $85 \%$ of its populations are rural and uneducated where as almost all of the European populations are urbanized and educated one.

On the other hand, this study showed that outpatient clinical follow up non-adherent schizophrenic patients are more than ten times vulnerable to the sufferings of Self-stigma than patients with good adherence to clinical follow up appointments. This finding is similar with previous result (20). This implies that higher self stigma could damage outpatient schizophrenia's strengths to maintain their clinical follow up, which in return may lead them to relapse and worsening severity of schizophrenia.

\section{Limitation Of The Study}

This study has some limitations. For example, by this study it was not possible to make clear the causality of the described associations as a result of the cross-sectional study design. The other limitation laid on the reason that the data were collected through scales; it was not possible subjective experiences of each individual schizophrenia outpatient.

\section{Conclusions}

This study didn't make sure the causal-effect relationship between the outcome variable and contributing factors. Despite the limitation, this study has several strengths. It has identified the current distribution of self stigma and associated factors among outpatients with schizophrenia in the northern Ethiopia where more than $27 \%$ of the populations are living below the poverty line. Besides, the uneducated, rural resident, and clinical follow up nonadherent persons with schizophrenia are at high risk of self stigma which is an indication 
for the national and international non-governmental charity organization to offer their interventions.

Moreover, this study suggests government primary and tertiary health institutions to design better psycho-social interventions that can help uneducated, single, rural residents, and clinical appointment non-adherent, and with no family support schizophrenia outpatients to have less self stigma and promote mental health and functioning.

\section{Declarations}

\section{Author's contribution}

All authors of this article had equal contribution in generating the study ideas (such as title selection, objective stating, and research methodology determination) during research proposal development, data analysis and write up, and manuscript preparation.

\section{Conflict of Interest}

All the authors declared no conflict of interest.

\section{Acknowledgment}

The researchers are thankful to Mekele University for supporting the study financially.

\section{References}

1. World Health Organization, the World Health Report, Approach to Mental Health, WHO, Geneva, Switzerland, 2002.

2. Health FDROEMO, National Mental Health Strategy 2012/13- 2015/16, Federal Democratic Republic of Ethiopia Ministry of Health, Addis Ababa, Ethiopia, 2012.

3. World Health Organization, the World Health Report, Approach to Mental Health, WHO, Geneva, Switzerland, 2001.

4. M. Razali, "Prevention of relapse and interventions for enhancing medication adherence in schizophrenia: an East Asian perspective," Asia-Pacific Psychiatry, vol. 2, no. 2, pp. 68- 76, 2010.

5. D. Base, Statistics by Country for Schizophrenia, US Census Bureau, 2004.

6. W. Corrigan, A. Kerr, and L. Knudsen, "The stigma of mental illness: explanatory models and methods for change," Applied and Preventive Psychology, vol. 11, no. 3, pp. 
179-190, 2005.

7. B. Ritsher and J. C. Phelan, "Internalized stigma predicts erosion of morale among psychiatric outpatients,” Psychiatry Research, vol. 129, no. 3, pp. 257-265, 2004.

8. T. Yanos, D. Roe, K. Markus, and P. H. Lysaker, "Pathways between internalized stigma and outcomes related to recovery in schizophrenia spectrum disorders," Psychiatric Services, vol. 59, no. 12, pp. 1437-1442, 2008.

9. L. Vogel, N. G. Wade, and A. H. Hackler, "Perceived public stigma and the willingness to seek counseling: the mediating roles of self-stigma and attitudes toward counseling," Journal of Counseling Psychology, vol. 54, no. 1, pp. 40-50, 2007.

10. Y M Laic P H Hong, CY I Chee, Stigma of Mental Illness, Singapore MedicalJournal, 2001 Mar; 42(3): 11-4.

11. Brohan, R. Elgie, N. Sartorius, and G. Thornicroft, "Self- stigma, empowerment and perceived discrimination among people with schizophrenia in 14 European countries: the GAMIAN-Europe study," Schizophrenia Research, vol. 122, no. 1-3, pp. 232-238, 2010.

12. Link, B.G., 1987. Understanding labeling effects in the area of mental disorders: an assessment of the effect of expectations of rejection. American Journal of Community Psychology 11, 261-273

13. Bifftu BB, Dachew BA. Perceived Stigma and Associated Factors among People with Schizophrenia at Amanuel Mental Specialized Hospital, Addis Ababa, Ethiopia: A CrossSectional Institution Based Study. Psychiatry journal. 2014 May 21; 2014.

14. Link, B.G., Mirotznik, J.D., Cullen, F.T., 1991. The effectiveness of stigma coping orientations: can negative consequences of mental illness labeling be avoided? Journal of Health and Social Behavior 32, 302-320.

15. Gerlinger G, Hauser M, Hert M, Lacluyse K, Wampers M, Correll CU. Personal stigma in schizophrenia spectrum disorders: a systematic review of prevalence rates, correlates, impact and interventions. World Psychiatry. 2013 Jun 1; 12(2): 155-64.

16. Domagoj Vidović, Petrana Brečić, Maja Vilibić and Vlado Jukić. Insight and Self-Stigma in Patients with Schizophrenia. Acta Clin Croat 2016; 55:23-28.

17. Asher L, Fekadu A, Hanlon C, Mideksa G, Eaton J, Patel V, et al. Development of a Community-Based Rehabilitation Intervention for People with Schizophrenia in Ethiopia. PLoS ONE, 2015: 10 (11): e0143572. doi:10.1371/journal.pone.0143572

18. Benti M, Ebrahim J, Awoke T, Yohannis Z, and Bedaso A. Community Perception towards Mental Illness among Residents of Gimbi Town, Western Ethiopia. Hindawi Publishing Corporation: Psychiatry Journal: Volume 2016, Article ID 6740346, 8 pages.

19. Vrbova K, Prasko J, Holubova M, Kamaradova D, Ociskova M, Marackova M, latalova K, Grambal A, Slepecky M, Zatkova M. self-stigma and schizophrenia: a crosssectional study. Neuropsychiatric Disease and Treatment. 2016:12 3011-3020. 
20. Haddad P, Brain C and Scott J. Nonadherence with antipsychotic medication in schizophrenia: challenges and management strategies. Patient Related Outcome Measures 2014:5 43-62.

\section{Figures}

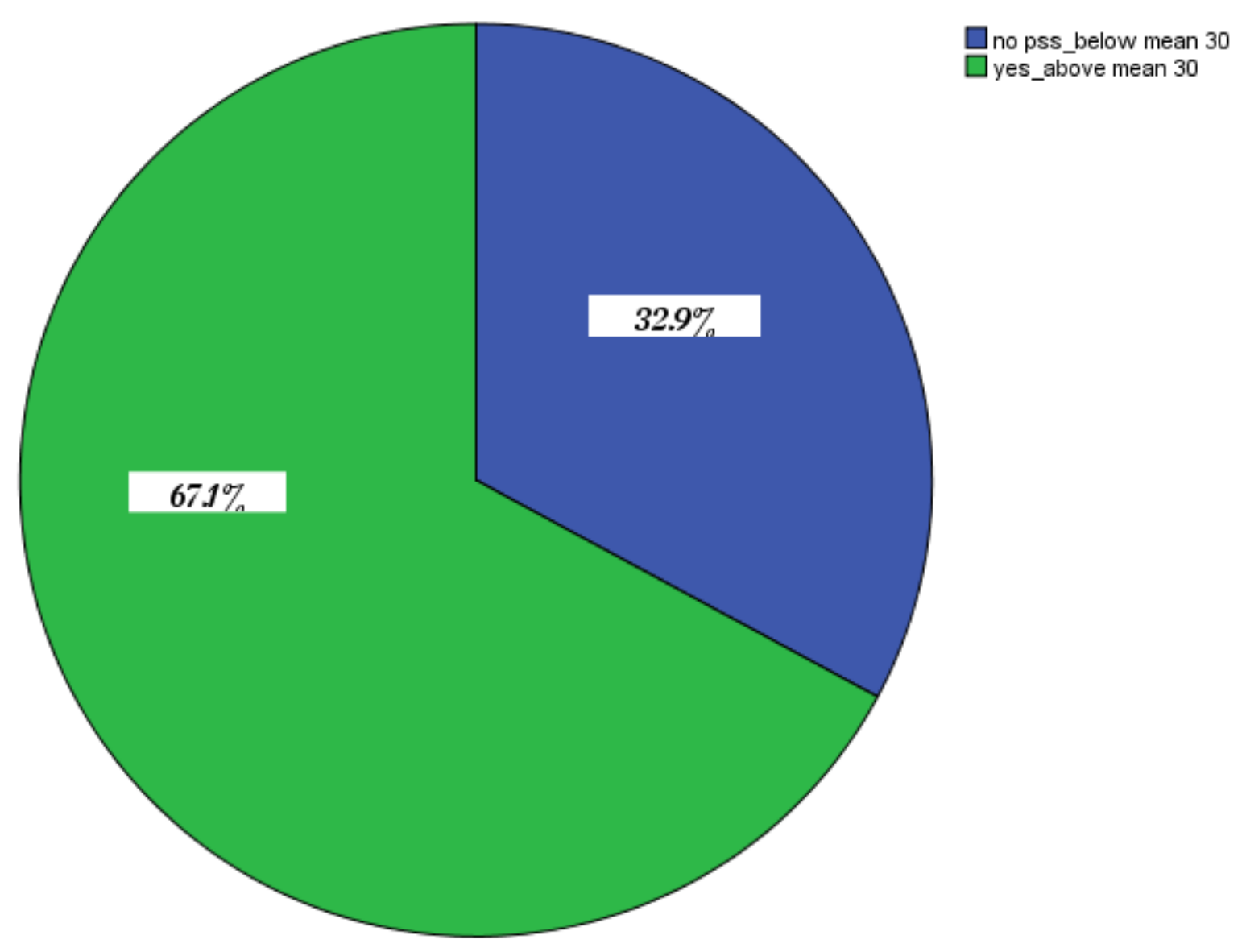

Figure 1: prevalence of self stigma among schizophrenia outpatients in low income country Ethiopia

\section{Figure 1}

Prevalence of Self-stigma and associated factors among Outpatients with Schizophrenia in low income East African countries: Ethiopia 